\title{
GRUNNEN TIL AT RETROFLEKS L SNART ER EINERÅDANDE I HOVUDSTADEN OSLO
}

\author{
ERNST HÅKON JAHR
}

\begin{abstract}
This paper describes a sound change involving the lateral system in Oslo Norwegian from ca. 1880 till today. From an early (c. 1880) system comprised of mainly one dental (or alveolar) $/ 1 /$ in all positions (except for an occasional retroflex [l] for the assimilated cluster [rl]), the retroflex [l] allophone spread during the 20th century to all phonological contexts except following an $[a(:)]$ or $[\mathrm{o}(:)]$ in a stressed syllable. Jahr $(1975,1988)$ claimed that this situation would probably prevail, and the sound change would not be completed and yield a simpler system, because of the attitude of Oslo speakers towards a low-status dialect feature associated with an area southeast of the capital. However, around the turn of the millennium, the development towards a simple one /1/ allophone system nevertheless continued, and children throughout the city started using the retroflex [l] also after $[a(:)]$ and $[o(:)]$. The last leg of this very long development could be completed, the author claims, because a large region around the capital in the last 50 years has aquired an oral variety based in the capital, but the speakers of this region did not have the negative attitude of the Oslo speakers towards the low-status dialect southeast of Oslo (the Østfold dialect). Therefore, the 'new' speakers of the mainly Oslo dialect, from the region around the capital, did not copy the 'strange' Oslo exception of the lateral system after the vowels $[a(:)]$ and $[o(:)]$, and this over the years came to have decisive impact also on the speech of young speakers from Oslo itself.
\end{abstract}

Key words: sound change, Oslo Norwegian, retroflex,

\section{Innleiing}

Etter tusenårsskiftet har det vore mange oppslag i norske aviser og i media elles om at det som blir kalla „Østfold-l”, har inntatt Oslo. Barn over heile byen bruker no ein /1/ i talespråket sitt som foreldre og andre assosierer med dialektane i Østfold. Mange av dei godt vaksne og eldre språkbrukarane i hovudstaden oppfattar det som skjer, som at „Østfold- $l$ ” er blitt innført frå Østfold til Oslo-talemålet. Ettersom Øst- 
fold-dialektane tradisjonelt har hatt svært låg status blant Oslo-folk, er langt frå alle glade for ei slik utvikling.

Ein av dei første til å nemne noko om dette på trykk, var forfattaren og lingvisten Helene Uri, som skreiv: „Og så er det noe som er i ferd med å skje med $l$-ene iallfall noen steder: Vi bor i Oslo, men mine barn og mange av deres venner har $l$-er som får dem til å høres ut som østfoldinger" (Uri 2004: 145).

I denne artikkelen skal eg vise at det på ingen måte er tale om nokon /1/ importert frå Østfold, noko Helene Uri naturlegvis også var klar over, sjølv om mange andre ser ut til å tru det. I staden er det slik at det som skjer i talespråket i Oslo no, er det siste stadiet $i$ ei lang utvikling av lateralsystemet i hovudstaden. Her skal vi såleis ta for oss det som viser seg å vera ein overgang frå eit enkelt system på slutten av 1800-talet med ein dental/alveolar [1] som hovudallofon til i dag da vi har eit nytt enkelt, men annleis system, nemleg med ein retrofleks [l] som hovudallofon av /1/-fonemet. I mellomperioden skal vi sjå at lateralsystemet var både komplekst og vanskeleg å beskrive. Det har likevel vore slik at den siste etappen på vegen fram til gjennomført bruk av retrofleks [l] i Oslo, også etter dei bakre vokalane /a/ og /o/, har vore vanskeleg å forklare. Her skal eg freiste å leggja fram ei forklaring. Artikkelen knytter dermed an til to andre eg nyleg har publisert om dette emnet, i festskrift til Gjert Kristoffersen og Katarzyna Dziubalska-Kołaczyk, begge i 2019. I ingen av desse arbeida har eg eigentleg lagt fram noka forklaring på kvifor den siste etappen i utviklinga no er skjedd.

Som eit utgangspunkt for det heile kan vi altså rekne Kristiania-talemålet mot slutten av 1800-talet. Kunnskap om stoda da, når det gjeld korleis $l$-lyden var på den tida, har vi frå samtidige skildringar av lydsystemet. Vi skal vidare stoppe og sjå kor langt endringa hadde kome ca. 1930, og så ein ny stopp på 1970-80-talet. I 1970- og 80-åra såg det ut til at lydendringa - strukturelt sett heilt umotivert - hadde stoppa opp rett før ho var fullført. Rimelegvis skjedde det på grunn av den negative språksosiale haldninga mange oslofolk hadde til den $l$-en dei altså plar kalle „Østfold-l”. For at lydendringa skulle bli heilt fullført, måtte også ein slik „Østfold-l” bli innført. Etter tusenårsskiftet er nettopp dette siste stadiet i $l$-utviklinga i ferd med å bli gjennomført i Oslo-mål.

\section{Starten rundt hundreårskiftet $1800 / 1900$}

Ved overgangen 1800/1900-talet hadde /1/-fonemet i talemålet til dei kondisjonerte i Kristiania/Oslo to allofonar: ein dental/alveolar allofon [1] og ein (langt mindre brukt) postalveolar allofon [1]. Den førstnemnde allofonen var avgjort den mest frekvente, og han blei brukt i dei aller fleste lydkontekstar og ord. Den postalveolare allofonen var til samanlikning lite brukt, men var ein mogleg uttale i ord som hadde $<\mathrm{rl}>\mathrm{i}$ skriftspråket, t.d. perle, herlig, farlig. Konsonantgruppa $<\mathrm{rl}>\mathrm{i}$ desse orda 
kunne også uttalast som r+l, [rl]. Denne uttalen blei utan tvil sett på som den mest formelle og korrekte, m.a. fordi uttalen da samsvarte med det ein fann i skrift.

Frå Knud Brekke (1881) og August Western (1889) har vi skildringar av lydane i danna Kristiania-tale rundt 1880. Dette var i ein periode da fonetikken utvikla seg raskt som vitskap. Ein prøvde så godt det let seg gjera å beskrive alle lydar i språket fonetisk nøyaktig. L-lyden i Kristiania blei da omtalt som ein ,,alveolær” konsonant, mens [l] blei sagt å vera „,supradental”. Ein av dei såkalla tre Store S-ane i utviklinga av fonetikken på den tida var professor Johan Storm i Kristiania. (Dei to andre S-ane var Eduard Sievers i Leipzig og Henry Sweet i Oxford.) Storm bidrog med transkripsjon av norske ord og setningar - etter datidas Kristiania-uttale - i ein reiseparlør (Bennett 1881). Storm stadfestar her at den dentale/alveolare $l$-uttalen var brukt i dei aller fleste kontekstar og ord, og han transkriberer $l$-ane i ord som alle, alt, folk, behold, lite, leve, gammel heilt likt. Hofgaard (1890: 22) skriv da også at „,ved $l$ fæstes tungespidsen mod tænderne”. Det er såleis ingen tvil om at i utganspunktet, mot slutten av 1800-talet, var hovudallofonen av $l$-fonemet i Kristiania dental, evt. alveolar.

Det er ikkje lett å forklare kvifor vi frå eit slikt utgangspunkt kunne få ei utvikling der den $l$-allofonen som hadde ein meir tilbaketrekt tungespiss (opprinneleg altså frå kombinasjonen $<$ rl $>$ ), no tok til å breie seg og etter kvart tok over for den dentale [1] i ord etter ord og i den eine lydlege konteksten etter den andre. Det hadde vore interessant å vita noko om korleis denne endringsprosessen i det heile tatt starta, for det er ein motsett prosess av det vi normalt skulle vente. Det som skjer, er altså at den $l$-allofonen som typologisk sett er markert, vinn fram. Ein dental [1] er utan tvil umarkert $i$ høve til ein postalveolar/retrofleks [l].

Det er god grunn til å tru at endringsprosessen starta på vestkanten i byen, dvs. i den varianten i Kristiania som hadde den høgaste sosiale prestisjen, ofte omtalt som talt riksmål. Amund B. Larsen gav i 1907 ut eit viktig arbeid om arbeidarklassespråket i Kristiania. Larsens skildring her representerer ei av dei første omfattande undersøkingane i verda av ein bydialekt, og Larsen er såleis ein tidleg sosiolingvistisk pioner (jf. Wiggen 1995, Jahr 2017). I Larsen (1907) skriv han ikkje noko om at ulike $l$-lydar er i bruk i arbeidarklassevarieteten i byen. Hadde utviklinga bort frå dental til retrofleks $l$-allofon starta i lågstatusvarieteten av Kristiania-mål - som er den Larsen skildrar - er det vanskeleg å tenke seg at denne endringa kunne ha spreidd seg såpass snøgt utover på 1900-talet som vi snart skal sjå at ho gjorde. Spreiinga tyder derfor klart på opphav i ein høgstatus talemålsvarietet.

Akkurat når det heile starta, veit vi dessverre heller ikkje. Rimelegvis var det relativt tidleg på 1900-talet. I førsteutgåva av uttaleordboka til Ivar Alnæs (1910: XII) finn vi ein viktig observasjon når det gjeld /rl/. Alnæs skriv at assimilasjonsproduktet [l] er av ein noko annan type enn den han fann som resultat av $/ \mathrm{rt} /, / \mathrm{rd} /$ og /rn/, som er [t, d, n]. I orda klart, fart, fordele og jern, som han bruker som døme, får vi lydar (altså [t, d, n]) som han kallar ,inverterte”, og han skildrar dei som „dumpe” 
og ,tykke” i klangen. Med [l] av /rl/ er det annleis, skriv han. $l$-en blir her ikkje like mykje forandra som $/ \mathrm{t} / \mathrm{og} / \mathrm{n} /$ blir saman med $/ \mathrm{r} /$, ,men tungespidsen trækkes noget bakenfor tændene". Han nemner orda farlig og kjcerlig som døme og meiner at $l$-en her ikkje blir ,invertert”. Med ,invertert” meiner han retrofleks, og det kan tyde på at den endringa vi følgjer i denne framstillinga, frå starten kunne skje fordi $l$-en $\mathrm{i} / \mathrm{rl} /$-ord enno ikkje hadde blitt retrofleks. I ord med /rt, rd, rn/ blei heilt klart assimilasjonsproduktet ein retrofleks (,,invertert”) lyd. Her ser vi da kanskje ein grunn til at [l] utover på 1900-talet relativt uproblematisk kunne erobre også framlydsposisjonen $\mathrm{i}$ ord, i motsetnad til [t, d, n]. Ingen av desse siste lydane kan vera framlyd i ord, det kan berre [l].

I denne artikkelen kallar eg [l] frå no av for „retrofleks”. Som vi ser av det som nettopp er sitert frå Alnæs (1910: XII), er ikkje det heilt uproblematisk. Den $l$-en som etter kvart etablerer seg som den mest frekvente $l$-allofonen i talemålet i Oslo, er blitt nemnd med svært mange ulike omgrep av dei som har diskutert han gjennom åra. Vi finn termar som „,supradental”, ,alveolar”, ,postalveolar”, ,retrofleks”, ,apiko-alveolar”, ,apiko-postalveolar”, „sublamino-prepalatal”, ,apikal” og kanskje fleire med. Moen og Simonsen (2012, jf. også 2005) gjer ein freistnad på å bestemme [l] eksperimentelt. Undersøkinga viser ein relativ stor grad av individuell variasjon, kanskje på grunn av at måleutstyret (som var i munnen) påverka artikulasjonen. Inger Moen og Hanne Gram Simonsen er òg merksame på at dei båe representerer, som eg, eit tidlegare stadium i utviklinga enn det vi finn i dag. Jamvel om den eksperimentelle undersøkinga deira ikkje er heilt eintydig, konkluderer forfattarane med at [l] er ,apikal”. Det er òg termen dei konkluderer med i artikkelen frå 2005 (p. 229).

Denne store omgrepsmengda for lyden [l] speglar rimelegvis at det finst eller fanst stor grad av individuell skilnad og variasjon, og at denne variasjonen kunne vera der utan at det akustiske og perseptuelle resultatet blei særleg påverka. Dette er likevel ikkje viktig for framstillinga her. Det er nemleg ikkje tvil om at det har skjedd ei endring ved at i hovudsak ein dental eller nær dental $l$ er endra til ein annan $l$ ved at tungespissen er trekt tilbake frå dental posisjon og no lager kontakt eit stykke lenger bak. Om tungespissen òg er bøygd bakover eller ikkje, er persepsjonelt ikkje avgjerande, og eg gjennomfører derfor, som Kolbjørn Slethei (1996: 46), omgrepet „retrofleks $l$ ” for [l] i denne historiske framstillinga.

Dei første som omtaler at skilnaden mellom [l] og ein meir velarisert dental, [1], er blitt viktig, er Olaf Broch og Ernst W. Selmer (1921). Broch var russiskfilolog og Selmer fonetikar, båe i Oslo. Dei skreiv at [1] blei brukt i det dei kalla „vulgærtalen” etter $[a]$ : [ha:ł d $a$ ka: 1$]$. Men, skriv dei, [1] „,høres klart også i dannet tale, f.eks. i ord som alle, bolle" (Broch og Selmer 1921: 66). Fram til krigen var uttalen med [1] vanleg i tradisjonell Oslo-dialekt, i arbeidarklassen, etter alle dei bakre vokalane $[a(:)],[\mathrm{o}(:)]$ og $[\mathrm{u}(:)]$, t.d. i ord som alle, ball, sal, kalle, holde, bolle, rolle, bolig, politi, skole, pol. 
Det skulle likevel gå lenge før fonetiske skildringar av norsk tok inn over seg at [1]-allofonen burde nemnast som viktig. Den første som etter krigen skreiv at den velariserte dentalen var tydeleg i talemålet i Oslo, var gresk-amerikanaren Kostas Kazazis (1968) ved University of Chicago. I ei melding i tidsskriftet Language av R.G. Popperwell (1963) nemnde han at [1]-allofonen var tydeleg å høyre på den lydprøva som følgde med boka. Popperwell sjølv hadde ikkje nemnt [1] som ein mogleg allofon i boka si frå 1963, som var om uttalen i norsk.

\section{0-stadiet i utviklinga}

Hjalmar Borgstrøm (1938) og Hans Vogt (1939) gir båe gode døme på at lydendringa rundt 1930 var komen eit godt stykke på veg. Rundt 1930 var variasjonen faktisk blitt ganske komplisert, og dei to norske struktualistpionerane strevde med å finne eit forståeleg synkront system. Det viste seg å vera vanskeleg. Borgstrøm (1938: 257f.) melder t.d. at ved ordet klok kan uttalen vera både med [1] og med [l], og han finn ingen regel eller ordning for bruken av dei to allofonane. Vogt følgjer opp og skriv t.d.: „In my own pronunciation the $l$ of skò:le 'a school' is the same as the $l$ of $n o: l i$ "nothern" (1939: 139). At det var slik, fordi vi da stod midt $i$ ei endring, kunne verken Borgstrøm eller Vogt vita. No i ettertid er det enklare å skjøna at grunnen til at desse to skarpe lingvistane hadde problem med å systematisere og finne ut av det dei kunne observere i språket hos seg sjølve og andre, var endringar på veg frå eitt enkelt system og mot eit nytt.

Vogt har altså oppdaga at ordet skole, som ikkje inneheld noko $<\mathrm{rl}>$, likevel kunne få uttale med [l]. Dette øydela den naturlege gruppa som både han og Borgstrøm rekna [t, d, n, l] med til. For dei tre lydane [t, d, n], altså unntatt [l], fanst det ikkje noko ord der dei er med utan at ein kan vise attende til ei konsonantgruppe med /r/. Bare [l] var unntak her, på grunn av den pågåande utviklinga av $l$-lyden frå dental til retrofleks uttale, og den utviklinga var altså verken Borgstrøm eller Vogt klar over.

Fleire lingvistar kom seinare til å gi bidrag til skildringa av det mellomstadiet i utviklinga som eg, litt vilkårleg, har sett til ca. 1930. T.d. nemner Gyda Dahm Rinnan (1969: 131) at [l] blir brukt ,i manges uttale: klo, blod, skole, mulig”, altså fleire ord der [l] ikkje kunne førast attende til noko <rl>. Dahm Rinnan var fødd 1922, og vi må gå ut frå at ho sjølv brukte [l] i dei orda ho nemner her. Eric Papazian (1977: 10-19) gir ei god skildring av variasjon og uvisse i bruken av [1] og [l] i det same mellomstadiet. Papazians eigen bruk av [1] og [1], slik han skildrar han i artikkelen, representerer klart dette stadiet i utviklinga (jf. Jahr 1977). Papazian meiner han har denne bruken av oslomål frå mor si (1977: 3). Det passar godt i tid med første halvdel av 1900-talet. 


\section{Situasjonen i 1970- og 80-åra}

Etter krigen heldt overgangen frå [1] til [l] fram. Fonetikaren Arne Vanvik (1972: 141) observerte følgjande i talemålet i Oslo:

In the last few decades / $/$ / seems to have been more and more superseded by [l] in the Oslo area. Oslo speakers of the younger generation mostly use a slightly retroflex lateral. This lateral can be heard in initial, medial and final position.

Vanvik nemner at $l$-en etter dei bakre vokalane $a$ og $a$ er unntak førebels, men meiner det berre er eit spørsmål om tid før [1] og [l] „have merged completely” (1972: 143).

I 1970-80 åra hadde vi nådd til eit stadium der den retroflekse allofonen hadde inntatt alle tenkelege posisjonar - unntatt akkurat etter $[a(:)]$ og $[\mathrm{o}(:)]$ i trykksterk staving (Jahr 1975, 1981, 1988 skildrar dette stadiet). Dersom [a(:)] og [o(:)] kom føre ein /1/ i trykksvak staving, blei likevel ofte [l] brukt i staden for [1]. Skilnaden kan vi observere i ord der det er mogleg å leggje trykket anten på første eller på andre staving: (en) alle, ballett, ballong, salong, kollasj. Alle desse orda vil kunne ha trykket anten på første eller på siste staving. Dersom trykket blir lagt på siste staving, blir sekvensane /al/og /ol/trykksvake, og da kan orda ha [l]: [ $a^{\prime}$ le], [b $a^{\prime}$ let], [s $\left.a^{\prime} \mid \mathrm{loy}\right]$, [ko' $\left.\mid a \int\right]$. Dette er den tradisjonelle trykkplasseringa i den talemålsvarieteten som frå gammalt av har høyrt heime på vestkanten i byen, i det høgstatus talemålet (talt riksmål) som ein fann blant dei betrestilte borgarane. Dersom trykket i desse orda i staden blei lagt på den første stavinga i ordet - noko som var typisk for arbeidartalemålet i byen - blei den velariserte dentalen [1] brukt: ['ałe], ['bałet] osb.

Også over morfemgrense kunne [l] følgje etter $[a(:)]$ og [o(:)] i ord som smålig [smo:li], grålig [gro:li], sålenge [so'leyə]. Også det spesielle ordet tralala høyrer vel til her. Trykkplasseringa i så lenge gjer dessutan at både trykket og morfemgrensa gir høve til [l] i akkurat det ordet. Ordet ale(i)ne kan på grunn av trykkplasseringa også ha [l]: [a'lenə]/[a'læinə].

Kvifor var det så unntak på dette stadiet (1970/80-åra) i lydendringa akkurat etter $[a(:)]$ og $[\mathrm{o}(:)]$ (i trykksterk stilling)? Frå eit strukturelt synspunkt er eit slikt unntak heilt umotivert og vanskeleg å forstå.

Den forklaringa som blei gitt i Jahr (1988) på at lydendringa - tilsynelatande på et heilt vilkårleg stadium - såg ut til å stoppe rett før fullføring, var den negativ haldninga som mange oslofolk tradisjonelt har hatt til dialektane sør i Østfold, og dermed frykten for å lyde som ein språkbrukar frå Østfold. (Om oslofolks haldninger til dialektane i Østfold, jf. Strømsodd 1979.) I Østfold blei den retroflekse $l$-en også brukt etter $[a(:)]$ og $[\mathrm{o}(:)]$ i trykksterk staving. Og det er berre [l] brukt etter $[a(:)]$ og $[o(:)]$ i trykksterk stode som blei og framleis blir omtalt som „Østfold- $l$ ”. 
„Østfold- $l$ " er naturlegvis ikkje ein eigen $l$. Det er i staden tale om fråværet av den velariserte og dentale [1]-allofonen etter $[a(:)]$ og [o(:)]. Derfor gir sjølve omgrepet „Østfold-l” stort sett berre meining i Oslo. Når derfor ,innføring av Østfold-l” er blitt slått stort opp i media dei siste 10-12 åra - i aviser, tv og radio - viser det berre kor grunnfesta det er hos mediefolk at det som er interessant i Oslo, meiner dei er interessant for heile landet. Fråværet av [1]-allofonen etter $[a(:)]$ og $[o(:)](=\varnothing$ stfold- $l)$ har for oslofolk vore eit av dei trekka som oftast blir nemnde som typiske for (dei sørlege) østfolddialektane (i ord som ball, salig, holde, mål osb.).

Eit klart indisium på at mange oslofolks tradisjonelt negative haldning til Østfold-dialekt har noko for seg som forklaring på at overgangen frå dental til retrofleks $l$ stoppa opp rundt 1970-80, er at folk som samstundes - men andre stader i landet eller i utlandet - av ein eller annan grunn voks opp med Oslo-dialekt, svært ofte hadde gjennomført dette siste stadiet i lydendringa og såleis brukte [l] også etter $[a(:)]$ og $[o(:)]$ i trykksterk staving. For desse språkbrukarane, som altså voks opp langt frå hovudstaden, spelar den negative haldninga hos mange oslofolk til Østfolddialekt inga rolle. Dette var t.d.. tydeleg blant ungdom med tilnærma Oslo-dialekt på Svalbard, som påvist og diskutert av Brit Mæhlum i hennar doktoravhandling om språkbruken i Longyearbyen (Mæhlum 1992: 258f.; jf. også nedanfor om austnorsk regionalmål).

\section{Det siste stadiet, som vi no er inne $i$}

Rundt tusenårsskiftet, eller mot slutten av 1990-talet, skjedde det likevel at den retroflekse $l$-en vann fram i Oslo også i den siste posisjonen etter $[a(:)]$ og $[o(:)]$ i trykksterk stode. Da det først skjedde, gjekk det raskt, og bruken var snart å høyre over heile Oslo. Likevel var, og er det ikkje slik at alle barn bruker [l] også etter $[a(:)]$ og $[\mathrm{o}(:)]$, men brukarane finst i alle bydelar.

Den til no einaste kvantitative undersøkinga av den siste etappen i lydendringa (Svendsen 2012) tyder på at bruken av [l] etter [a(:)] og [o(:)] var klart individuell i perioden 2004-2008, da Svensens data blei samla inn. Det var ikkje slik at alle unge språkbrukarar i Oslo hadde denne bruken, mange hadde han framleis ikkje. Men det var ikkje mogleg for Svendsen å peike på språksosiale faktorar som kunne definere bruk/ikkje-bruk. Verken bydel eller sosialgruppe, etnisk bakgrunn, kjønn eller utdanning hos foreldra - ingen av dei tradisjonelle faktorane i ei sosiolingvistisk undersøking såg ut til å kunne fange inn bruken, var konklusjonen til Svendsen i 2012. Når vi i dag finn heilt gjennomført bruk av [l] etter $[a(:)]$ og $[o(:)]$ hos ein ung stortingsrepresentant frå Oslo Høgre (Mathilde Tybring-Gjedde), og bruken dessutan er fullt ut akseptert av NRKs nyhendemedarbeidarar og korrespondentar, ser heller ikkje prestisje/ikkje-prestisje ut til å vera eit kriterium som spelar noka rolle. 


\section{Kva sette i gang den siste etappen?}

Men kva var det rundt tusenårsskiftet som gjorde at den siste demninga brast, og at det å høyrest ut som ein østfolding ikkje lenger var nok til å hindre gjennomføringa av den siste etappen fram til det siste stadiet i lydendringa?

Fleire har meint at immigrantar og framandkulturelle språkbrukarar har spela ei viktig rolle i dette (sjå t.d. Aftenposten nr. 464, 30.11. 2011, s. 16), men den siste utviklinga kan neppe forklarast slik. Etnisk norske språkbrukarar tar sjeldan etter andre etnonorske varietetar. Det som derimot er viktig å sjå på, er det vide austnorske regionalmålet som har utvikla seg dei siste to-tre generasjonane. Hovudstadsmålet har hatt stor innverknad på eit vidt område på Austlandet. Likevel er det ikkje slik som mange har trudd, at det er talemålet i Oslo med den høgaste statusen (talt riksmål) som breier seg utover og jamnar ut dialektskilnader. Det er i staden det folkelege talemålet i Oslo, tidlegare kalla Vika-mål eller austkantmål, som har gjort det.

For oss no, og det vi diskuterer her i denne framstillinga, har likevel dette med høg/låg status lite, eller ikkje noko å seia, etter det vi kan sjå. Og når det gjeld akkurat bruken av [1] eller [l] etter $[a(:)]$ og [o(:)] i trykksterk staving, var det - igjen så lang vi veit - ikkje nokon skilnad på dei sosialt ulike talemåla i hovudstaden. Men da det folkelege hovudstadsmålet tok til å breie seg utover mot nord, sør, aust og vest i ein stor sirkel (sjå Gulbrandsen 1977 (om Tønsberg), Torp 1988, 1997, Thoengen 1994 (om Hallingdal), Tvitekkja 1998 (om Vest-Telemark), Sørensen 1998 (om Moss) og Skramstad 1999 (om Hadeland)), var oslofolks haldning til østfolddialektane utan betydning. Dei områda rundt Oslo som blei fanga inn i den språklege regionaliseringa frå hovudstaden, tok etter svært mykje frå oslotalemålet. Men det var gode språkstrukturelle grunnar til at dei ikkje skulle ta etter bruken av [1] etter $[a(:)]$ og [o(:)]. Derfor tok mange av dei i staden i bruk [l] her, som var det språkleg sett opplagte valet. For desse språkbrukarene, mange av dei langt utanfor Oslo, var det ingen språksosial grunn til å halde på [1] som ein $l$-allofon til å bruke berre etter $[a(:)]$ og $[\mathrm{o}(:)]$. Den velare $l$-allofonen [1] hadde med det ikkje noko grunnlag lenger, og den siste etappen i lydendringa blei så gjennomført hos mange som tok i bruk det austnorske regionalmålet. Alle desse språkbrukarane, brukarane av regionalmålet med utspring i Oslo, og som no i prinsippet kunne seiast å vera oslomålsbrukarar, var så, etter det vi må tru, langt viktigare som pådrivarar for ei endring også inne i sjølve Oslo - enn det framandkulturelle språkbrukarar kunne vera med sine etnonorske varietetar. Og når først prosessen var sett i gang i Oslo, slo bruken snøgt igjennom hos individuelle språkbrukarar over heile byen. Det er i dag neppe nokon grunn til å tru at bruken av [1] etter $[a(:)]$ og $[\mathrm{o}(:)]$ vil halde stand i lang framtid. Dagane for [1]-allofonen er ganske sikkert talte, og [l]-allofonen vil herske totalt, slik den dentale [1]-allofonen gjorde mot slutten av 1800-tallet. 


\section{Frå eit enkelt lateralsystem til eit nytt i løpet av noko over 100 år}

Vi har følgt endringa i lateralsystemet i talemålet i Oslo gjennom meir enn 100 år, frå ca. 1880 til i dag. Frå eit enkelt system i utgangspunktet med i hovudsak éin dental $l$-allofon er vi raskt i ferd med å nå fram til eit like enkelt, men nytt system, no med ein retrofleks $l$ som hovudallofon. I den mellomliggjande perioden har vi sett ei ganske komplisert utvikling, og vi har stoppa ved to mellomstadium, ein stopp rundt 1930 og ein i 1970-80-åra. Studiet av heile dette lydendringsforløpet har vist korleis overgangen har skjedd dels frå ord til ord, dels frå kontekst til kontekst, og vi har sett korleis - mot slutten - språksosiale faktorar spela inn som ei bremse ei tid før vi fekk gjennomføringa av det aller siste stadiet $i$ endringa: da [l] tok over for [1] også etter $[a(:)]$ og $[o(:)]$ i trykksterk staving. Da det endeleg bar til med denne endringa i Oslo, og da over heile byen, men individuelt og enno ikkje hos alle, er det god grunn til å tru at det skjedde fordi språkbrukarar utanfor Oslo, som talte det regionalmålet som var blitt danna som ein påverknad frå hovudstadsmålet, hadde gjennomført den same endringa først. Hos dei var haldninga til østfoldmål inga hindring eller bremse. Når dei først hadde gjennomført endringa, var det ikkje mogleg lenger å stå imot i sjølve Oslo heller.

\section{Litteraturliste}

Aftenposten nr. 464, 30.11. 2011.

Alnæs, I. 1910. Norsk uttaleordbok. Utgit av Bymaals-laget. Kristiania: Aschehoug.

Bennett, T. 1881. A selection of phrases for tourists travelling in Norway. Fourth edition, enlarged and revised by Johan Storm. Christiania: H. Tønsberg's Printing-office.

Borgstrøm, C.H. 1938. „Zur Phonologie der norwegischen Schriftsprache (nach der ost-norwegischen Aussprache)." I: Norsk Tidsskrift for Sprogvidenskap 9. 250-273. Omsett til norsk i: Jahr, E.H. og O. Lorentz 1981. (red.): Fonologi / Phonology (= Studier i norsk språkvitenskap / Studies in Norwegian Linguistics 1). Oslo: Novus. 170-186.

Brekke, K. 1881. Bidrag til dansk-norskens lydlcere. (Separataftryk af Aars og Voss's skoles indbydelsesskrift for 1881.) Kristiania: W. C. Fabritius. Opptrykt i: Jahr, E.H. og O. Lorentz. 1981. (red.): Fonologi / Phonology (= Studier i norsk språkvitenskap / Studies in Norwegian Linguistics 1). Oslo: Novus. 17-78.

Broch, O. og E.W. Selmer. 1921. Håndbok i elementer fonetik. Kristiania: Aschehoug.

Gulbrandsen, P.P. 1977. „Hvor går de østnorske bymåla?” I: Språklig Samling 18. 1.

Hofgaard, S.W. 1890. Omrids af lydlceren. Tillceg til Norsk grammatik til skolebrug. Kristiania: Aschehoug.

Jahr, E.H. 1975. „1-fonemet i Oslo bymål.” I: Norskrift Nr. 1 (= Talemålsundersøkelsen i Oslo (TAUS). Skrift nr. 1). Arbeidsskrift for nordisk språk og litteratur. Universitetet i Oslo: Institutt for nordisk språk og litteratur. 3-15.

Jahr, E.H. 1977. „Svar og kommentar til Eric Papazians artikkel 'Om 'tjukk l' og andre rare lyder.” I: Norskrift Nr. 14. Arbeidsskrift for nordisk språk og litteratur. Universitetet i Oslo: Institutt for nordisk språk og litteratur. 57-67. 
Jahr, E.H. 1981. „L-fonema i Oslo bymål.” I: Jahr, Ernst Håkon og Lorentz, Ove: Fonologi / Phonology (= Studier i norsk språkvitenskap / Studies in Norwegian Linguistics 1), Oslo: Novus. 328-344. Opptrykt i Jahr, E.H. 2008. Språkhistorie og språkkontakt / Language History and Language Contact. (Red.: Wiggen, Geirr; Bull, Tove; Nielsen, Marit Aamodt.) Oslo: Novus. 80-96.

Jahr, E.H. 1988. „Social dialect influence in language change: the halting of a sound change in Oslo Norwegian.” I: Fisiak, J. (red.): Historical Dialectology: Regional and Social (= Trends in Linguistics, Studies and Monographs 37), Berlin-New York: Mouton de Gruyter. 329-335. Opptrykt i Jahr, E.H. 2008. Språkhistorie og språkkontakt / Language History and Language Contact. (Red.: Wiggen, Geirr; Bull, Tove; Nielsen, Marit Aamodt.) Oslo: Novus. 130-135.

Jahr, E.H. 2017. „A pioneering sociolinguistic concept: Amund B. Larsen and his discovery in the 1880s of neighbour opposition as a socio-psychological mechanism in linguistic change - and its rediscovery in the 1980s as hyperdialectism." I: European Journal of Scandinavian Studies 47(2). 308-319.

Kazazis, K. 1968. [Melding av Popperwell, R. G.: The pronunciation of Norwegian (1963).] Language 44. 632-633.

Larsen, AB. 1907. Kristiania bymål. Vulgærsproget med henblik på den utvungne dagligtale. Kristiania: I kommission hos Cammermeyers boghandel.

Moen, I. og H.G. Simonsen. 2005. „Artikulasjon av apikale likvider i østnorsk: /l, r, r/.” I: Lie, Svein; Nedrelid, Gudlaug og Omdal, Helge (red.): MONS 10. Utvalde artiklar frå det tiande Møte om norsk språk i Kristiansand 2003 (= Forskningsserien nr. 47, Høgskolen i Agder, Kristiansand). Kristiansand: Høyskoleforlaget. 219-229.

Moen, I. og H.G. Simonsen. 2012. „Likvider i østnorsk: fire urokråker?” I: Røyneland, Unn og Enger, Hans-Olav (red.): Fra holtijaR til holting spåkhistoriske og språksosiologiske artikler til Arne Torp på 70-årsdagen. Oslo: Novus. 221-238.

Mæhlum, B. 1992. Dialektal sosialisering. En studie av barn og ungdoms språklige strategier i Longyearbyen på Svalbard (= Tromsø-studier i språkvitenskap 12). Oslo: Novus.

Papazian, E. 1977. „Om ‘tjukk 1' og andre rare lyder.” I: Norskrift 14. Arbeidsskrift for nordisk språk og litteratur. Universitetet i Oslo: Institutt for nordisk språk og litteratur. 1-56.

Popperwell, R.G. 1963. The pronunciation of Norwegian. Cambridge-Oslo: Cambridge University Press.

Rinnan, G.D. 1969. „Nok en gang om alveolarene.” I: Tilegnet Carl Hj. Borgstrøm. Et festskrift på 60-årsdagen 12.10.69 fra hans elever. Universitetsforlaget: Oslo-Bergen-Tromsø. 128-133. Opptrykt i: Jahr, E.H. og O. Lorentz. 1981. (red.): Fonologi / Phonology (= Studier i norsk språkvitenskap / Studies in Norwegian Linguistics 1). Oslo: Novus. 273-277.

Skramstad, T. 1999. Oslocirkumferensen og språklig regionalisering. Upublisert cand. philol.avhandling, Universitetet i Oslo, Institutt for nordistikk og litteraturvitskap.

Slethei, K. 1996. Grunnbok i fonetikk for språkstudenter. Oslo: Cappelen Akademisk.

Strømsodd, S.A. 1979. Dialektholdninger blant folk i to bydeler i Oslo. Upublisert cand. philol.-avhandling, Universitetet i Oslo, Institutt for nordisk språk og litteratur.

Svendsen, B.A. 2012. „Et språklig bakholdsangrep? ‘Østfold L-ens’ inntog i Oslo.” I: Røyneland, Unn og Enger, Hans-Olav (red.): Fra holtijaR til holting spåkhistoriske og språksosiologiske artikler til Arne Torp på 70-årsdagen. Oslo: Novus. 349-365.

Sørensen, M. 1998. Vi snakkce'ke 'dialekt i Moss! En sosiolingvistisk undersøkelse av språkvaner hos mossinger. Upublisert cand. philol.-avhandling. Universitetet i Bergen, Nordisk institutt.

Thoengen, V. 1994. „Hallingmål eller bokmål?” I: Språklig Samling 35. 2.

Torp, A. 1988. , 'Hu skøyt høl i huet'.” I: Språklig Samling 29. 6-9.

Torp. A. 1997. „Hva skjer med bokmålet? I: Språklig Samling 38. 10-12.

Tvitekkja, S. 1988. Talemålsendring og sosial variasjon. Ei gransking av sosiolingvistiske tilhøve i Vinje $i$ Vest-Telemark. Upublisert cand.philol.-avhandling. Universitetet i Oslo, Institutt for nordistikk og litteraturvitskap. 
Uri, H. 2004. Hva er språk? Oslo: Universitetsforlaget.

Vanvik, A. 1972. „A phonetic-phonemic analysis of standard eastern Norwegian. Part I.” I: Norsk Tidsskrift for Sprogvidenskap/Norwegian Journal of Linguistics 26. 119-164.

Vogt, H. 1939. „Some remarks on Norwegian phonemics.” I: Norsk Tidsskrift for Sprogvidenskap 11. 136-144. Opptrykt i: Jahr, E.H. og O. Lorentz. 1981. (red.): Fonologi / Phonology (= Studier i norsk språkvitenskap / Studies in Norwegian Linguistics 1). Oslo: Novus. 187-195.

Western, A. 1889. „Kurze Darstellung des norwegischen Lautsystems.” I: Phonetische Studien 2 (Zeitschrift für wissenschaftliche und praktische Phonetik mit besonderer Rücksicht auf die phonetische Reform des Sprachunterrichts). Marbug in Hessen. 259-282. Omsett til norsk i: Jahr, E.H. og O. Lorentz. 1981. (red.): Fonologi / Phonology (= Studier i norsk språkvitenskap / Studies in Norwegian Linguistics 1). Oslo: Novus. 79-96.

Wiggen, G. 1995. „Amund B. Larsen som sosiolingvist.” I: Kulbrandstad, Lars Anders og Øygarden, Bjarne (red.): Peilepunkter. Festskrift til Thor Ola Engens 50-årsdag 11. januar 1995. Vallset: Oplandske Bokforlag. 20-38. 